\title{
"PAU PRA TODA OBRA": AS VIVÊNCIAS DE PRAZER E SOFRIMENTO NO TRABALHO DE PROFESSORES SUBSTITUTOS DE UMA UNIVERSIDADE FEDERAL
}

"Jack- of- for- all trades": The experiencies of pleasure and suffering in the work of substitute teachers of a public higher education institution

'Un jean fait tout": les expériences de plaisir et de souffrance au travail d' enseignants suppléants d'une université fédérale

"Los toderos": las vivencias de placer y sufrimiento en el trabajo de profesores substitutos de una universidad federal

\begin{abstract}
Alessandra Cristine Filgueiras Rates ${ }^{1}$
Mestre em Psicologia pela Universidade Federal do Maranhão’-UFMA (2015). Especialista em Psicopedagogia pelo Centro de Ensino Superior Dom Bosco-UNDB (2011). Graduação em Psicologia pela Universidade Federal do Maranhão-UFMA (2009). Graduação em Pedagogia pela Universidade Estadual do Maranhão-UEMA

(2008). Docente de Psicologia na graduação do Instituto de Ensino Superior Franciscano-IESF. Docente na Secretaria Municipal de Educação-SEMED. Psicóloga na Secretaria Municipal da Criança e Assistência Social-
\end{abstract}

SEMCAS.

Denise Bessa Léda ${ }^{2}$

Doutora em Psicologia Social pela Universidade do Estado do Rio de Janeiro (2009) Docente da Universidade Federal do Maranhão desde 1992, atualmente nível Associado III (DE). Professora permanente do Programa de Pós-Graduação em Psicologia da Universidade Federal do Maranhão (PPGPSI).

Líder do Grupo de Pesquisa Sociedade contemporânea, mundo do trabalho e processos de subjetividade.

Principais temas de pesquisa: mundo do trabalho, trabalho docente e educação superior. Integra a coordenação colegiada do Grupo de Pesquis a História, Sociedade e Educação no Brasil (HISTEDBR), no Maranhão. Membro da Rede UNIVERSITAS/BR, do grupo de trabalho Política de Educação Superior (GT11) da Associação

Nacional de Pesquis a e Pós-graduação em Educação (ANPED) e do grupo de pesquisa Psicodinâmica e Clínica do Trabalho da Associação Nacional de Pesquisa e Pós-graduação em Psicologia (ANPEPP).

\section{Resumo}

Este artigo analisa as vivências de prazer e sofrimento no trabalho de professores substitutos de uma universidade federal, a partir das peculiaridades desse vínculo. Adotou-se uma aproximação entre os fundamentos teórico-metodológicos da Psicodinâmica do Trabalho, do Materialismo HistóricoDialético e da Sociologia do Trabalho, as quais compreendem o trabalhador enquanto dotado de subjetividade, agente na construção e transformação do seu trabalho. Realizou-se pesquisa de campo com amostra proposital de nove docentes substitutos da Universidade Federal do Maranhão-UFMA, de áreas do saber variadas, em exercício, no ano de 2014, e dois chefes de departamento da mesma instituição. Os resultados apontam vivências de prazer e sofrimento com impactos na identidade docente e predomínio de estratégias de defesa individuais.

Palavras-chave:Professor Substituto; Universidade Federal; Prazer-Sofrimento.

\footnotetext{
1 alessandrarates@gmail.com

2 denise.bessa.leda@gmaill.com.br
} 


\begin{abstract}
This study analyzes the experiencies of pleasure and suffering in the work of substitute teachers of a public higher education institution. The theoretical framework includes dialogues between Work Psychodynamics, Historical Materialism-Dialectic and Sociology of Work, understanding workers as subjects, agents and transformers of reality professional. This is a qualitative field research, whose participants are nine substitute teachers, in office, and two department heads of the Federal University of Maranhão, in 2014. The results point to a labor context of pleasure and suffering, with impacts on identity. The use of individual defenseive strategies was predominant.
\end{abstract}

Key-words: Substitute Teacher; Public University; Pleasure- Suffering.

\title{
Résumé
}

Cet article analyse les particularités des expériences de plaisir et souffrance dans le travail des enseignants suppléants d'une université fédérale, sour la caractéristique du type de contrat de ces travailleurs. On a approuvé une approximation entre les fondements théorico-méthodologiques de la Psychodynamique du Travail, Matérialisme Historique-Dialectique et la Sociologie du Travail, dont les domaines de connaissance comprennent le travailleur doté de subjectivité. On a mené une recherche sur le terrain avec un échantillon de neuf enseignants suppléants de l'Université Fédérale de MaranhãoUFMA, de différents domaines d'expertise en 2014, et deux chefs de département de la même institution.Les résultats présentent des expériences de plaisir et souffrance, avec impacts sour la identité. Ils sont enclins a utiliser des stratégies de défense individuelles.

Mots clés: Enseignant suppléant; Université fédérale; Plaisir-souffrance

\section{Resumen}

Este artículo analiza las vivencias de placer y sufrimiento en el trabajo de profesores substitutos de una universidad federal, a partir de las peculiaridades de ese vínculo. Se adoptó una aproximación entre los fundamentos teórico-metodológicos de la Psicodinámica del Trabajo, del Materialismo HistóricoDialéctico y de la Sociología del Trabajo, las cuales comprenden al trabajador en cuanto dotado de subjetividad. Se realizó una investigación de campo con una muestra de nueve docentes substitutos de la Universidad Federal de Maranhão-UFMA, de áreas del saber variadas, en ejercicio, en el año 2014, y dos jefes de departamento de la misma institución. Los resultados apuntan vivencias de placer y sufrimiento con impactos en la identidad docente y predominio de estrategias de defensa individuales.

Palabras claves: Profesor Substituto, Universidad Federal, Placer- Sufrimiento.

\section{Introdução}

A figura do professor substituto desenvolve-se, predominantemente, nas universidades federais, a partir da década de 90, do século XX, conforme Pinto (2010). Anteriormente outras nomenclaturas foram utilizadas para denominar os docentes fora da carreira, ou seja, eram os aulistas e horistas.
No início dos anos 90 do século passado, no governo Collor, ocorrem os primeiros processos de privatização do Estado, com reflexos na educação pública, com a limitação de concursos públicos para docentes nas universidades federais, problemática essa que também perdurou no governo FHC. 
Assim, em meio a um contexto de privatizações, e preocupados com a retirada de direitos e benefícios, muitos professores do ensino superior concluíram que o melhor caminho seria a antecipação de suas aposentadorias, visando, assim, minimizar perdas e/ou buscar outras funções melhor remuneradas e de maior reconhecimento social (Zorzo, 2010).

Resulta que a saída encontrada pelas universidades federais, para suprir o déficit de docentes resultou em contratação de professores, então denominados substitutos. Neste mesmo período, outro fator importante a ser ressaltado foi $o$ estímulo/exigência à qualificação docente em nível de doutorado, pois muitos professores efetivos receberam licenças para capacitação, o que também desencadeou a contratação de docentes substitutos. E embora o governo tenha autorizado concursos públicos para o provimento de professores efetivos, ainda assim o número de nomeações sempre foi inferior ao necessário para repor o quadro docente, o que levou à permanência da figura do professor substituto nos quadros das universidades federais.

A contratação desses professores é regida pela lei $\mathrm{n}^{\circ} 8.745 / 93$, que disciplina a contratação por tempo determinado para atender necessidade temporária de excepcional interesse público, que não poderá ultrapassar percentual máximo de
$20 \%$ do total de docentes efetivos em exercício na instituição. Com base nessa legislação, os critérios de contratação dos professores substitutos acontecem em casos de: suprir falta de professor de carreira nos casos de exoneração ou demissão, aposentadoria, falecimento, licença ou afastamentos obrigatórios.

A lei 12.772/2012, que norteia a carreira do magistério superior federal também abrange o professor substituto, definindo que a contratação do mesmo deverá ser autorizada pelo dirigente da instituição, condicionada à existência de recursos orçamentários e financeiros para fazer frente às despesas decorrentes da contratação e ao quantitativo máximo de contratos estabelecido para a universidade. Além disso, essa lei ainda trata da carga horária referente a este vínculo, com o regime de trabalho de 20 ou 40 horas semanais.

O que vem ocorrendo, principalmente nos últimos anos, e Koehler (2006) chama a atenção para isso, é a substituição dos professores efetivos, alicerçada pela cultura de que os substitutos necessitam de menores investimentos, porque geram menor custo para a instituição.

Nesse sentido, o professor substituto apresenta-se como mais uma ferramenta à acumulação de receitas do Estado, acirrada pela justificativa de um Estado enxuto, cujo 
objetivo é cortar gastos, mesmo que o discurso utilizado procure sustentar $\mathrm{O}$ contrário. Assim, “(...) a contratação de professores substitutos vem sendo uma saída econômica para o sustento das universidades, que infelizmente se naturalizou no cotidiano de diversas unidades, sendo mesmo incentivada acriticamente por muitos" (Mancebo, 2007, p.77).

Segundo o Ministério da Educação (MEC, 2012), nas universidades federais, entre 2008 e 2012, houve importante salto no número de docentes efetivos com a autorização de 21.786 novas vagas docentes e a consequente redução de $64 \%$ de docentes substitutos. Entretanto, embora tenha ocorrido esta ampliação do quadro de professores efetivos, a mesma foi insuficiente para compensar o déficit dos anos anteriores e, novamente, os substitutos foram convocados a sanar esta falta.

De acordo com Vieira (2014), no site Globo Educação, em 12 de março de 2014, a Associação de Docentes da Universidade Estadual do Rio de JaneiroUERJ (Aduerj) informou que nessa instituição 900 professores substitutos respondem por mais de $50 \%$ de toda a carga horária lecionada. À época, já havia uma ação judicial movida pelo Ministério Público do Rio de Janeiro tentando impedir o excesso de contratações por tempo determinado, pois as mesmas não estariam atendendo situações de excepcional interesse ou necessidade temporária, uma vez que se repetia há anos, em detrimento dos concursos para professores efetivos, problemática que ainda persiste, segundo Latieri (2017).

Em contextos de crise econômica e financeira, como assiste-se atualmente, nota-se que novamente a figura do professor substituto é convocada para preencher lacunas e dificuldades das instituições. Já é possível observar a abertura de processos seletivos simplificados em várias instituições federais, em detrimento dos concursos públicos.

Neste ínterim, este artigo visa analisar as vivências de prazer e sofrimento no trabalho dos professores substitutos de uma universidade federal, a partir das peculiaridades do tipo de contrato, uma vez que estes professores não gozam de estabilidade no trabalho, tal qual o restante do quadro docente. Entende-se que a não permanência, característica destes profissionais, é uma variável que influe ncia o fazer docente e, ao mesmo tempo, repercute na sua saúde e subjetividade, trazendo ambivalências entre prazer e sofrimento.

\section{Método}

Para esta investigação, realizo u-se pesquisa de campo com amostra de nove 
docentes substitutos da Universidade Federal do Maranhão (UFMA), de áreas do saber variadas, em exercício, no ano de 2014, e dois chefes de departamento da mesma instituição, visto que estes, muitas vezes, tendem a escutar as queixas dos professores substitutos e são responsáveis pela organização do trabalho docente, como carga horária e distribuição de disciplinas. A caracterização da amostra foi diversificada quanto ao sexo, idade, estado civil, nível de titulação, entre outros.

$\mathrm{O}$ instrumento de coleta de dados utilizado foi a entrevista semiestruturada para todos os participantes, entrevistas estas que foram gravadas e, em seguida, transcritas na íntegra. Somente, no caso dos professores substitutos, houve também a aplicação de um questionário socioeconômico, a fim de fazer uma aproximação desses dados com a análise da fala dos docentes. Os entrevistados assinaram o Termo de Consentimento Livre e Esclarecido, garantindo a liberdade em participar e a confidencialidade de suas identidades, bem como opiniões. Ainda de maneira a adequar-se aos parâmetros éticocientíficos exigidos, a pesquisa passou por aprovação do Comitê de Ética em Pesquisa (CEP) da UFMA.

Iniciou-se a pesquisa de campo entrevistando um chefe de departamento de curso de graduação, posteriormente este indicou um professor substituto do seu departamento e, assim, foram ocorrendo as recomendações dos demais professores participantes, que eram sugeridos pelos chefes para serem sujeitos dessa pesquisa.

Nesse sentido, a amostra foi do tipo proposital, em que vão sendo identificados os casos de interesse a partir da própria população que está sendo pesquisada, ou seja, por meio dos próprios entrevistados (Nogueira-Martins \& Bógus, 2004). Assim, participantes foram indicados por outros participantes.

$\mathrm{Na}$ temática em questão, pretendeuse realizar uma aproximação entre os fundamentos teórico-metodológicos da Psicodinâmica do Trabalho, Materialis mo Histórico-Dialético e da Sociologia do Trabalho. Tal interlocução mostrou-se possível, à medida que estas áreas do saber compreendem o trabalhador enquanto dotado de subjetividade, agente na construção e transformação do seu trabalho e identidade. Para isto, referem-se à atribuição e ou significação dos discursos deste trabalhador por meio da dimensão dialética, baseada nos aspectos históricos e sociais do homem, não excetuando-se os aspectos subjetivos, particulares a qualquer indivíduo, concebendo a categoria trabalho no bojo de suas contradições. Tais fundamentos buscam desvelar a rede ideológica tecida para a manutenção da ordem vigente, que naturaliza as condições sociais e incute em cada indivíduo 
referenciais que the retiram a possibilidade de construir sua vida como sujeito autônomo, dotado de singularidade e participante ativo da sociedade a que pertence.

$$
\text { Esses alicerces teórico- }
$$

metodológicos podem ser entendidos como abordagens críticas e qualitativas acerca das categorias deste estudo, pois veem a realidade de modo complexo e multifacetado, em suas imbricações sóciopolíticas-econômicas. Estão afinados com uma visão de homem que vai além do reducionismo patologizante, integrando uma perspectiva crítica, pois o trabalhador está sempre dentro do contexto da organização do trabalho, na qual repousam condicionantes histórico-sociais, objetivos e subjetivos. Busca-se na análise dos dados e na articulação com as discussões teóricas desta pesquisa respeitar os subsídios desses referenciais, de igual modo, definiu-se como categorias principais para este estudo: trabalho; subjetividade e professor substituto.

Acredita-se que esta pesquisa possa contribuir para reflexões sobre a saúde e subjetividade dos professores substitutos das instituições públicas de ensino superior, uma vez que apresentam vínculo frágil de trabalho, precarizando-se em busca de melhorar o currículo, visando retornarem como docentes efetivos para essas instituições. Tudo isto a partir de uma lógica de acumulação flexível, gerencialista estatal, que prevê enxugamentos, ao máximo, preferindo processos seletivos simplificados a concursos públicos.

\section{Resultados e discussão}

\section{A Acumulação Flexível e suas repercussões na subjetividade do professor substituto da UFMA}

Para Marx (1989), o homem é um sujeito do trabalho, de modo que o trabalho torna-se condição para sua definição e existência. Desse modo, o trabalho adquire caráter ontológico, singularizando o ser humano, por meio dos processos de transformação da natureza.

O trabalho adquire sentido, redimensionando o dia a dia, permitindo autorrealização nas esferas simbólica, social e afetiva ao trabalhador. Antunes (2005a) afirma que o sentido do trabalho envolve ainda reflexões sobre o processo capitalista de produção por meio de ideologias, hegemonias e discursos.

O sentido do trabalho na visão de Costa (2013), é uma representação individual e/ou coletiva delineada por desdobramentos cotidianos, organizacionais, políticos, econômicos, culturais e sociais.

"Particularmente, eu gosto do que eu faço. Gosto de trabalhar mesmo." (Professor 2). 
"Rapaz, eu costumo dizer sempre pros meus alunos que o trabalho ele dignifica o homem. Então, acima de tudo, o trabalho pra mim é realização, é realizar." (Professor 5).

A representação que cada professor substituto tem do seu trabalho, os sentimentos envolvidos, seus pensamentos e julgamentos constroem o sentido do mesmo, que contribui para ofuncionamento de sua saúde mental.

Ao longo dos séculos, a relação do homem com o trabalho foi se redimensionando, incorporando novas características e impactos significativos ao fazer do trabalhador, principalmente a partir do padrão capitalista de acumulação flexível, na década de 70, que incidiu diante do contexto de desregulamentações e flexibilizações dos sistemas produtivos, comprimindo a relação espaço-tempo, envolvendo rápidas mudanças, principalmente no setor de serviços, dentre eles, a educação.

Tal modo de produção também é designado toyotismo, em decorrência de muitos dos seus princípios terem sido iniciados na fábrica japonesa de veículos Toyota, apresentando como características principais: estoques reduzidos; produção just in time (na hora); trabalhadores polivalentes (perfil multitarefa); utilização de novas tecnologias; desregulamentação dos contratos de trabalho, contratos flexíveis; empresas transnacionais, dentre outras.

O toyotismo ocorre sob o prisma neoliberal da mundialização do capital, predominando o comércio exterior, com surgimento de oligopólios mundiais.

A mundialização é o resultado de dois movimentos conjuntos, estreitamente interligados, mas distintos. $\mathrm{O}$ primeiro pode ser caracterizado como a mais longa fase de acumulação ininterrupta do capital que o capitalismo conheceu desde 1914. O segundo diz respeito às políticas de liberalização, de privatização, de desregulamentação e de desmantelamento de conquistas sociais e democráticas (Chesnais, 1996, p. 34).

Um forte princípio do toyotismo é a fábrica magra, numa referência ao enxugamento de tudo o que for considerado excessivo ou supérfluo, tanto no que se refere aos estoques, quanto à quantidade de trabalhadores. Tal fábrica é capaz de funcionar com efetivo reduzido e sujeito às instabilidades do mercado, sem perder a produtividade. Assim, os trabalhadores permitem uma nova racionalização, com ênfase à polivalência, flexibilizando processos de trabalho, mas também trabalhadores. (Coriat, 1994). 
Ao reduzir o efetivo de trabalhadores, a reestruturação produtiva traz de modo muito acentuado o fenômeno do desemprego estrutural, um dos componentes principais do conceito de Antunes (2005b), a nova classe-que-vivedo-trabalho. Esta nova classe é composta, tanto pelos trabalhadores desempregados, formadores de um exército de reserva, quanto por empregados, em sua maioria, por vínculos precários, informais, temporários, subcontratados, part-time, com poucas garantias trabalhistas, tornando-se, assim, adequados à lógica do capital neoliberal.

Encontra-se, no contexto referido, o professor substituto das instituições federais de educação superior o qual se inscreve na nova classe-que-vive-do-trabalho, pois pertence a uma categoria laboral sem estabilidade no trabalho, não perene, custando menos ao Estado.

Outro ponto que também diz respeito à nova classe-que-vive-dotrabalho, é que as carreiras tradicionais em uma única empresa estão fenecendo, pois o trabalhador deve demonstrar capacidade de empregar-se rapidamente em quaisquer instituições, além de apresentar um grande leque de habilidades e qualificações. Contraditoriamente, observa-se uma verdadeira corrida pela estabilidade pelas vias do emprego público.
No caso dos professores substituto s entrevistados, observou-se além do interesse pela estabilidade, a expectativa de pertencimento ao quadro de efetivos. “ $A$ expectativa é entrar aqui na universidade como efetivo." (Professor 4). “Eu já fiz dois concursos, e agora eu tô esperando um edital da UFMA." (Professor 8).

Observa-se que a categoria trabalho apresenta redimensionamentos, porém não perde seu lugar de centralidade, modificamse apenas as estruturas que compõem o processo produtivo. Antes esta era marcada pelo operariado industrial, hoje há um constante aumento da nova classe-que-vivedo-trabalho, atingida não apenas em sua materialidade, mas, principalmente, com profundas repercussões na sua subjetividade.

No padrão capitalista de acumulação flexível, a subjetividade do trabalhador passa a ser elemento de centralidade absoluta no processo produtivo, pois a matéria-prima do trabalho imaterial, como o trabalho docente, é a subjetividade. Nesse sentido, as tecnologias funcionam como ferramentas importantes de controle da subjetividade do trabalhador, convocando-o a trabalhar mesmo quando o tempo deveria ser de não trabalho. Entretanto, tal convocação é realizada de forma sedutora, a partir de um viés de uma suposta rapidez, capaz de organizar e facilitar a vida do trabalhador, como nota-se abaixo. 
Então, hoje, ainda bem, a gente tem as possibilidades da utilização dos incrementos tecnológicos... então email, whatsapp, enfim. Os próprios sistemas eles ajudam muito a gente a atender a demanda desse [trabalho] Nem sempre é uma demanda presencial. Às vezes é a análise de um relatório, de uma planilha e enfim, e a gente vai tentando atender. (Professor 7).

A recomposição produtiva promoveu a diminuição das hierarquias nas empresas, observando-se um envolvimento das equipes em prol da produtividade, onde cada trabalhador não se ocupa somente do seu trabalho, mas exerce, ainda, um verdadeiro controle e influência sobre o desempenho do outro.

Ocorre, assim, a exasperação da competitividade no ambiente laboral, dentro da lógica neoliberal, em que o trabalhador convive ainda com a sensação frequente de culpa por, muitas vezes, não conseguir atingir as exigências e metas cada vez maiores do mercado (Guareshi, 2001).

Além disso, também há o medo eminente de ser excluído a qualquer momento do processo produtivo, uma vez que a própria ideologia prega que o trabalhador é responsável por sua empregabilidade, ou seja, mostrando sua capacidade de tornar-se empregável, por meio de qualidades e competências valorizadas pelo mercado (Ramos, 2002).

Nesse sentido, tem-se a seguinte fala: "Porque é assim, se a gente não tiver bagagem, não tiver experiência o mercado de trabalho joga a gente pra debaixo do tapete, né? Então, eu tô aí na ativa" (Professor 1).

O trabalhador, desse modo, em tempos de neoliberalismo convive com a permanente sensação de insegurança, construindo sua subjetividade a partir do instável, do medo do desconhecido, do individualismo e da competição. É nesse cenário que os professores das instituições públicas de educação superior estão inseridos: numa cultura acadêmica pautada em ideais gerenciais, exigindo um perfil atrelado aos princípios de flexibilidade e empreendedorismo (Ribeiro \& Leda, 2016).

Os professores substitutos, por sua vez, convivem com a insegurança na renovação dos contratos, com o isolamento por não conseguirem conviver e trocar experiências com os colegas, dado o excesso de trabalho e até de empregos para manter um determinado padrão de subsistência.

Nesse sentido, os dados desta pesquisa demonstraram que para $88,88 \%$ dos professores substitutos entrevistados, esta é a primeira oportunidade como substituto. E ainda boa parte deles está na segunda ou terceira renovação contratual, 
pois $11,17 \%$ possuem até 6 meses, $55,50 \%$ possuem de 7 meses a 1ano e 33,33\% possuem quase 2 anos no cargo de professor substituto. Também infere-se que, para a maioria dos entrevistados, o trabalho como professor substituto também significa a primeira experiência como docente.

Dos professores substitutos entrevistados $77,77 \%$ conciliam seu trabalho como substituto com o exercício de outra atividade laboral e somente $22,23 \%$ não possuem outra atividade profissional. Assim, infere-se que tais profissiona is necessitam ter vários empregos para conciliar um padrão de consumo satisfatório, permitindo-se sobrecarga de trabalho em prol de maior consumo e status social.

$\mathrm{O}$ individualismo incentivado pelo padrão capitalista de acumulação flexível trouxe ainda reflexões no aspecto coletivo dos trabalhadores, pois não conseguem muitos espaços de discussão, somada à falta de confiança e descrédito nas instituições classistas.

Nesse sentido, para Alves (2007), delineia-se atualmente o estrangulamento e a redução do poder e alcance dos sindicatos combativos e autônomos, assim, muitos questionamentos e reclamações tendem a ser vistos como uma inadaptação ao mundo do trabalho, tornando o trabalhador mais suscetível às futuras demissões.
A narrativa de alguns dos professores substitutos entrevistados demonstra desinteresse em participar do movimento sindical.

"Eu não sei como é que eu me encaixaria no sindicato, com um contrato temporário. Já fui até convidada pra participar. (...) Mas por enquanto eu ainda não tive muita vontade de ir atrás." (Professor 2).

"Eles não tão conseguindo nem pros professores efetivos, imagine pros substitutos (...)” (Professor 8).

Considerando a reestruturação produtiva do mundo do trabalho contemporâneo e suas repercussões sobre a subjetividade do professor substituto da UFMA, cabe agora refletir sobre os impactos na saúde deste profissional, nos aspectos de prazer e sofrimento no trabalho.

\section{A Subjetividade dos professores substitutos da UFMA: entre vivências de prazer e sofrimento no trabalho}

O artigo em questão concebe a saúde a partir das relações com a organização do trabalho, admitindo desdobramentos sociopolíticos. Ou seja, o trabalho possui dimensão complexa e polissêmica, podendo tanto ser condição de humanização e dignidade, contribuindo para a saúde do indivíduo, quanto condição alienante, fonte de adoecimento e estruturante. 
A saúde, na perspectiva teórica da Psicodinâmica do Trabalho de Christophe Dejours, desenvolvida a partir da década de 90 do século passado, seria um movimento constante de luta, uma verdadeira negociação que o indivíduo faz ao enfrentar as adversidades. Neste entendimento, saúde não significa ausência de doença ou sofrimento, mas a possibilidade de administrar as dificuldades e o mal-estar, pois o sofrimento é inerente ao trabalho e a todas as organizações, à medida que todo trabalho tem algum tipo de insatisfação e/ou aflição.

O foco passa a ser não somente o adoecimento, mas também o não adoecimento do trabalhador, considerando a possibilidade do trabalho em constituir-se de modo a desestabilizar o equilíbrio psicossomático do indivíduo, levando-o a um constante processo de luta contra o sofrimento, sublimando-o.

A Psicodinâmica do Trabalho investiga as repercussões das organizações e modos de gestão do trabalho sobre a subjetividade e a saúde dos trabalhadores. Segundo Dejours (1992), a organização do trabalho compreende a divisão do trabalho ou de tarefas e a divisão dos homens. A divisão do trabalho ou de tarefas pauta-se nas prescrições para a implementação da tarefa, ou seja, seu conteúdo. Já a divisão dos homens diz respeito à estrutura hierárquica presente na organização, os controles, práticas de gestão, os projetos e valores os quais os trabalhadores estão submetidos.

Para Dejours (1992), a organização do trabalho exerce sobre o homem uma ação peculiar, com impacto no aparelho psíquico, ou seja, na subjetividade do homem, pois ao trabalhar o sujeito entra em choque com sua história individual, seus sonhos, desejos e projetos, emergindo, assim, as vivências de prazer e sofrimento.

Nesse sentido, coube investigar as particularidades da dinâmica prazer e sofrimento no trabalho destes professores, tornando-se importantes os seguintes questionamentos: Como esses trabalhadores estabelecem suas estratégias de defesas visando suportar as adversidades do trabalho e evitar o adoecimento? Como percebem sua identidade profissional, nesse contexto de precarização?

A saúde, segundo a visão dejouriana é pautada na ambivalência prazer e sofrimento, conforme descreve o professor a seguir: "Quando eu ouço trabalho, dá cansaço, mas ao mesmo tempo, prazer”. (Professor 2).

Dejours (2004) traz importante contribuição sobre as diferenças existentes entre trabalho prescrito (aquele que possui descrição formal ou é legitimado em rubrica legal) e trabalho real (aquele que de fato acontece), enquanto uma esfera de sofrimento para o indivíduo, pois é 
impossível prever antecipadamente todas as especificidades e variabilidades do trabalho. O trabalho real dá-se na relação direta com a organização do trabalho e com os colegas, não sendo possível a nenhum trabalhador a previsão total do mesmo.

$\mathrm{O}$ conflito entre o real e o prescrito no trabalho do professor substituto pode ter início logo no seu processo de adaptação na universidade, tendo sido apontado como aspecto de sofrimento, principalmente, pela percepção de não acolhimento e, ao mesmo tempo, isolamento, dentro da instituição. "Quando você está entrando aqui, você não sabe direito onde é que são as coisas, onde, que e o quê que vocêtem que fazer (...) Você fica meio perdido". (Professor 4).

Outro ponto de frequente sofrime nto trazido pelos docentes substitutos, diz respeito a pouca autonomia, diante da organização do trabalho, o que resulta em mais dificuldades para lidar com o real. Eis os relatos:

"Mas das reuniões que eu participei do semestre passado, praticamente todas, eu vejo que o professor substituto não tem voz. Ele não tem voz. Ele não tem voz." (Professor 5)

“(...) assim, eu até brinco que ali a gente é pau pra toda obra, [grifo nosso] então assim, a gente não pode dizer que não por que a gente é substituto, sabe?" (Professor 6).
A falta de autonomia do professor substituto demonstra sua submissão frente ao departamento, como o gestor aponta a seguir.

“(...) é que ele acaba aceitando todo tipo de trabalho que lhe determinam (...)É raro um professor substituto que chega e se impõe." (Gestor 1).

Frequentemente, além de muitos departamentos disponibilizarem pouca autonomia e liberdade criadora ao professor substituto, este profissional, ainda, muitas vezes, esbarra com os preconceitos e humilhações por parte de alguns professores efetivos, como nota-se nos seguintes depoimentos.

"Então, acho que assim, por eu ser substituta já enfrentei tipo assim humilhação mesmo. Do colega dizer pra mim que isso não era da minha conta porque afinal de contas eu era só substituta." (Professor 2).

Alguns departamentos, por meio de gestão fiscalizadora, abrem espaço para o controle do trabalho do substituto, até que o mesmo prove sua capacidade de trabalho e responsabilidade, como revela a seguinte fala:

"Porque, o professor (...) Inclusive, no começo, no horário da aula da gente, ele subia pra ver se a gente estava no laboratório dando aula. Fiscalizava. Pedia pros técnicos tambémficarem de olho na gente, se 
a gente faltava ... $O$ primeiro semestre ficam desconfiando de vidraria que quebrou. Foi o substituto que não reparou o aluno. Sempre achando que é do substituto [culpa], que o substituto é descuidado, porque tá passando só uma temporada. (...) E aí depois dos primeiros 6 meses que a gente fica trabalhando direitinho, sem faltar, sem nada, aí é que eles têm mais confiança e deixam a gente trabalhar mesmo sossegado, normal." (Professor 9).

$\mathrm{O}$ conflito entre o prescrito e o real, traz à tona o que a teoria da Psicodinâmica do Trabalho denomina de estratégias defensivas ou estratégias de defesa, que funcionam como arranjos construídos pelos trabalhadores, de forma individual e coletiva, visando atenuar a percepção do sofrimento no trabalho (Moraes, 2013).

Porém, tais estratégias não são capazes de promover a emancipação do sujeito, podendo, inclusive, conduzir à alienação ou ter sua eficácia diminuída. As estratégias defensivas utilizadas pelos professores substitutos entrevistados foram as defesas de proteção, adaptação e exploração.

As defesas de proteção utilizam o mecanismo da racionalização das causas geradoras do sofrimento, balanceando o funcionamento dos modos de pensar e agir do trabalhador, evitando o adoecimento. Não são capazes de alterar a situação da organização do trabalho, levando o indivíduo à alienação, a longo prazo (Mendes, 2007).

A fala a seguir expressa uma defesa de proteção: "Mas eu não vejo como um peso. Vejo como uma oportunidade, cada disciplina que eu pego aqui, pra mim é uma oportunidade de estudar, de conhecer mais gente, de conhecer mais alunos" (Professor $3)$.

Sobre uma discussão com um professor efetivo, um professor substituto racionaliza, demonstrando outra defesa de proteção.

"Ele falou diretamente pra mim. Falou: Olha não é nada pessoal, mas é que eu acredito mesmo que sem o doutorado não tem como você contribuir com a universidade. Eu falei: Você realmente acredita nisso? (...) Mas eu não fiquei chateada. Na verdade, assim pelos alunos eu não me chateio nunca." [grifonosso] (Professor 3).

No que diz respeito a trabalhar sob pressão no seu departamento, um professor substituto demonstra um modo de pensar compensatório, revelando uma defesa protetiva. "Mas, você, você se acostuma, né, e é até mesmo bom, tu trabalhar assim sob pressão, porque aí tu vais te 
acostumando, né." (Professor 7, grifo nosso).

As defesas de adaptação, por sua vez, atuam sob o fundamento da negação do sofrimento do trabalhador, submetendo-o ao discurso da organização, subsumindo seu desejo ao desejo do capital, em prol do ideal de produtividade difundido.

No relato a seguir, o professor demonstrou o mecanismo de adaptação, evitando entrar em confronto com a organização do trabalho, naturalizando o conformismo diante das pressões.

"Então deixa tudo ficar quieto (...)

O cara se afastou para fazer um doutorado, voltou, ele voltou. A cadeira que ele ministrava é dele.

Por natureza. Normal, tranquilo. Quem vai discutir por conta disso? Acho natural, sem problema." [grifonosso] (Professor 4).

Do mesmo modo funcionam as defesas de exploração, também sob o fundamento da negação, pela autoaceleração do ritmo de produção do trabalhador, ocorrendo ainda a introjeção de metas organizacionais como se fossem objetivos pessoais do trabalhador.

Observa-se que, muitas vezes, os professores substitutos entrevistados sentem-se convocados a sempre ir além de suas atribuições, ou aumentar seu ritmo de trabalho, sobrecarregando-se em uma tentativa de mostrar empenho e disponibilidade à organização do trabalho.

"Eu tô substituindo um professor que tá viajando, numa quinta disciplina, às sextas-feiras." (Professor 3).

"Eu compro luvas pros alunos." (Professor 8).

"Fico, às vezes, também à disposição de aluno (...) Aí no período que eu não tô preparando a aula, ministrando aula, eu fico preparando roteiro, vou lá nos técnicos, separo o material." (Professor 9)

Corroborando as falas acima, um gestor admite: "O professor substituto como sabe que ele está com os dias marcados, contados, então, ele atende muito bem" (Gestor 2).

Assim, fica claro o esforço do professor substituto para demonstrar um bom trabalho, além de parecer haver uma expectativa do departamento sobre este tipo de dedicação extra.

Um gestor alerta que a disposição do professor substituto e sua permanente tentativa de mostrar-se competente, frequentemente, é utilizada em favor da organização do trabalho, que tende a explorá-lo. “Geralmente é uma pessoa mais nova com muita disposição pra trabalhar, de aprender também, né? O que é um fator positivo. Mas acaba que ele vem pra tapar 
muito buraco, que, muitas vezes, não é bem próprio do perfil acadêmico dele" (Gestor 1).

Observa-se, assim, no trabalho dos professores substitutos entrevistados a captura de sua subjetividade, de maneira sutil, pela aceitação da sobrecarga de trabalho, a qual, não raro, inclui a naturalização da intensificação das jornadas, como uma forma de mostrar certo tipo de excelência, pois se sentem sempre com suas capacidades em teste.

Dessa forma, nota-se que a captura da subjetividade dos professores substitutos dá-se pela submissão consentida, além de constituir-se em um rico controle pela organização do trabalho, uma vez que ocorrem relações de produção e, ao mesmo tempo, relações de poder.

"A gente sabe como é que funcionam as coisas (...) Se eu penso em algum momento ingressar numa instituição como professor, como efetivo do quadro, eu tenho que entender que, enquanto professor substituto, tô sendo avaliado constantemente" (Professor 7).

O termo "captura da subjetividade" cunhado por Alves (2000) implica uma prisão psíquica, uma espécie de cárcere mental alienante, do qual o indivíduo dificilmente consegue livrar-se, haja vista a sutileza e sofisticação engendradas pela organização do trabalho.
De forma complementar Faria (2013) designa o conceito de sequestro da subjetividade o qual atua na liberdade do sujeito. Ou seja, os pensamentos, valores, afetos e ideologias do trabalhador estão na posse da organização do trabalho, mas que podem ser recuperadas por este.

$O$ fato de a subjetividade ser sequestrada não significa que a mesma não é ou não pode ser capturada pela organização, mas que esta não é a forma predominante. A captura remete ao envolvimento total, a uma alienação e submissão plenas, a uma quase impossibilidade de fuga, enquanto o de sequestro sugere que há uma forma de resgate, sendo que o preço deste resgate, do regresso à liberdade, é o enfrentamento de relações sociais hostis em uma organização em que os sujeitos não são considerados confiáveis, adequados, inseridos, comprometidos. (Faria, 2013, p. 387)

Dado o medo atual do desemprego e a busca constante pela empregabilidade pode-se inferir que tanto a organização do trabalho, quanto os contextos do mercado educacional neoliberal são fatores influenciadores na dialética prazer e sofrimento no trabalho do professor substituto.

No caso dos professores substitutos entrevistados, além de suavizar o sofrimento, as estratégias defensivas podem estar gerando alienação, situação em que os 
esforços do indivíduo se concentram em defender a própria estratégia, relegando ao plano secundário a defesa do sofrimento propriamente dito.

A seguir, o discurso de um professor demonstra que as estratégias defensivas utilizadas pelo mesmo encobrem o seu sofrimento, pelo fundamento da negação, gerando alienação, ao aceitar a exploração de seu trabalho, submetendo-se ao discurso da organização.

"Mas assim o meu trabalho eu não tenho preguiça (...) Então, eu sou muito responsável, eu venho nos dias que eu não tenho aula, mas eu tô aqui. Participo de qualquer coisa que me chamar, de comissão, de reunião, eu topo (...)" (Professor 1). No caso do professor substituto, a elaboração das estratégias defensivas coletivas pode encontrar mais dificuldades, pois estas se estabelecem pela convivência com os pares, ao longo do tempo, na organização do trabalho. Ocorre que o substituto permanece pouco tempo na instituição, e mesmo nela, nem sempre consegue manter contato suficiente com os colegas para elaboração de defesas coletivas, como pode-se notar no seguinte depoimento: "Os professores que eu conheci (...) então essa parte relacional acaba ficando quebrada assim. Então, a gente percebe que entre eles professores efetivos têm uma história, eles já viram muitas coisas juntos e a gente, assim, passa e vai" (Professor 3).

Entende-se que para os professores substitutos entrevistados são mais comuns as defesas individuais, pois não ficam tempo suficiente na instituição para o contato com os colegas de profissão e, consequentemente, elaboração das defesas coletivas. Entretanto, infere-se que esta ausência possa estar trazendo impactos no que se refere à proteção e reação dos trabalhadores, pois ajudariam na defesa do sofrimento psíquico, no que fosse comum a todos.

Também se pode observar nos professores substitutos o que Dejours (2004) denomina de sofrimento patogênico, quando ocorrem o esgotamento das defesas psíquicas e o uso de estratégias defensivas do trabalhador, permanecendo, assim, a sensação de fracasso, incompetência, impossibilidade de reverter os problemas, acompanhado de patologias psíquicas e somatizações, muitas vezes, fazendo uso indiscriminado de psicofármacos. Quando o sujeito não consegue mobilizar-se frente às adversidades impostas pela organização do trabalho, ou seja, quando ao trabalhador não é mais possível a negociação entre o sujeito e a realidade imposta, o sofrimento patológico entra em ação.

Assim, os professores substitutos entrevistados expressaram alguns exemplos de sofrimento patogênico. 
“Já interferiu (...) Foi um semestre que eu ganhei dinheiro, digamos assim, mas qualitativamente eu perdi muito. Voltava com dores nas costas, estresse, eu perdi qualidade em sala de aula, que chegava em sala de aula ... cansado (...)” (Professor 5).

"Na minha saúde, tem interferido assim ... porque uma vez eu fui diagnosticada com estafa (...) provavelmente era um pico de pressão alta em função do estresse, da rotina, né?" (Professor 6).

"Olha, no período passado eu tava muito estressada, estressada assim de chegar o fim de semana, tu chegava a segunda-feira mais cansada, entendeu? De tanta coisa que tu tinha pra fazer." (Professor 8).

O sobretrabalho a que os professores substitutos estão submetidos também possui repercussões nas esferas social e familiar, acentuando o sofrimento destes trabalhadores, pois, em tempos neoliberais, o trabalho avança nas várias dimensões da vida do indivíduo.

“Então, hoje mesmo eu recebi uma ligação da escola que ela tava chorando, com saudade da mamãe, essas coisas. Fico com dó! (...) Então, eu acho que esse semestre a minha carga horária acabou extrapolando." (Professor 3).

“(...) eu tenho me sentido realmente cansada em relação a todas essas demandas (...) Já foi, inclusive, ... problema até com o meu relacionamento, né? O fato (...) Porque assim, você termina expediente dez horas da noite e o namorado quer sair... Cara, por favor, tô morta! (risos)” (Professor 6).

Interessante ressaltar que o professor substituto pode ter dificuldade em construir sua identidade docente em função do caráter transitório do vínculo, conforme o seguinte depoimento "Eu ainda acho que eu estou professor, até por ser substituto. Eu não me sinto profissional professor" [grifo nosso] (Professor 7).

$\mathrm{Na}$ fala do professor 7 observa-se um conflito, explicado por Macêdo e Heloani (2013, p. 223):

Todas são identidades construídas para atender à condição de estar no mundo. Porém, também se é levado a assumir duas ou mais identidades que podem concorrer entre si e gerar conflitos. Parece-nos, portanto, que é difícil dissociar a identidade pessoal da identidade social, uma vez que ambas fazem parte da mesma pessoa.

Alguns departamentos ainda fazem uma distinção literal entre os professores, como nota-se na fala a seguir. "E lá no 
departamento a gente é identificado assim

mesmo ela é substituta [grifo nosso]." (Professor 9).

Outro professor destaca um comentário de um professor efetivo, que o desqualificava enquanto docente de menosvalia, ou ainda aquele com quem $o$ departamento não pode fazer planos. "Eujá percebi assim algum comentário do tipo a professora (...) é só substituta” (...) [grifo nosso]. Ou então ah, mas a (...) nem vai tá aqui mesmo no ano que vem, sabe. Não dá pra contar com professor substituto. Coisas assim. (Professor 3).

Para Ciampa (1989, p.63), a identidade configura-se como uma totalidade que guarda dialeticamente as noções de diferença e igualdade. "Sucessivamente, vamos nos diferenciando e nos igualando". No caso do professor substituto, este iguala-se à categoria dos docentes, na prática da atividade de ensinar e, ao mesmo tempo, diferencia-se porque essa ação tem um caráter transitório, em função do tipo de vínculo (contrato por tempo determinado) com a instituição.

Ao mesmo tempo, outros professores conseguem revelar uma identidade docente, percebendo que são importantes à formação dos alunos e se percebem professores, independentemente, do tipo de vínculo.
"Eu me sinto professor da instituição, sinto que dou minha contribuição.” (Professor 4).

“Еu sou um professor. (...) apesar de ter um tempo de contrato, isso não vale pra nada no meu profissionalismo." (Professor 5).

Especialmente na contemporaneidade, a identidade do sujeito está em uma dinâmica de construção, que é influenciada pela pluralidade de ambientes e relações sociais, dentre as quais as laborais, demandando-lhe adaptações diversas, seja no seu fazer, seja no conviver com os pares. Desse modo, o professor substituto vai construindo e reconstruindo sua identidade, a partir do seu saber-fazer e nas interações entre colegas de trabalho e alunos, sendo ainda condição para sua saúde mental.

À medida que a identidade constitui o alicerce da saúde mental, identifica-se que "o trabalho pode constituir uma segunda oportunidade" na construção do equilíbrio psíquico e, por consequência, da saúde mental (Macêdo \& Heloani, 2013, p. 222).

Embora as vivências de sofrime nto possivelmente sejam muito presentes no trabalho do professor substituto, estas se dão em ambivalência com as de prazer. Portanto, para a teoria da Psicodinâmica do Trabalho, o sofrimento também pode conduzir às mobilizações de saúde, transformando-o em prazer. 
O sofrimento, para Dejours (2004), pode ser transformado em prazer, pois sendo o sofrimento criativo, ligado ao exercício da inteligência astuciosa, inscreve a relação de trabalho como mediadora da realização de si mesmo, contribuindo para a formação da identidade do sujeito trabalhador.

Nesse sentido, há de se esclarecer que, para a Psicodinâmica do Trabalho, a relação existente entre reconhecimento, identidade e sentido do trabalho funciona como sustentáculo da saúde do trabalhador.

Segundo Lima (2013, p.351), reconhecimento "é a forma da retribuição simbólica advinda da contribuição dada pelo sujeito, pelo engajamento de sua subjetividade e inteligência no trabalho". Apresenta-se de dois modos: o julgame nto de utilidade, que se estabelece nas relações com chefes e clientes, em um sistema hierárquico de modo vertical, e confere ao trabalhador sua legitimidade na esfera do trabalho e o julgamento de beleza, vivenciado na relação com os pares e, portanto, em linha hierárquica horizontal, o que possibilita ao trabalhador o seu pertencimento a um grupo profissional.

Alguns professores substitutos apresentaram falas destacando o reconhecimento de seu trabalho pelo julgamento da utilidade.

"Os alunos normalmentefalam isso. Professora, a gente gosta de professor substituto porque ele tá mais preocupado em dar aula pra gente do que com as brigas de departamento." (Professor 3).

"Muitos deles sim falam: Ah! (...) a tua aula é legal, tal, tudo." (Professor 9)

Ainda no que se refere ao julgamento de utilidade, observa-se o reconhecimento do trabalho dos professores substitutos quando os mesmos são convocados pelos alunos a falar de temas diversos às suas disciplinas, significa ndo para estes que são dignos de respeito e confiança.

"Eles mandam mensagens todo dia. Professora, eu li num livro, tipo assim, coisa que não tem nada a ver comigo até. (...) não estou achando no google, o que é que isso? Pô, às vezes, eu tô mega cheia ocupada, cheia de coisas, mas não, eu paro e vou responder. Porque eu acho que isso aqui é o que volta, né. O salário não aumenta por isso. Então, o que aumentaé o pessoal, são os alunos, os comentários. Isso é o que vale a pena." (Professor 2).

"Mês passado eu já fui até convidada pra ser nome de turma. A minha primeira turma. Então, eu fiquei extremamente emocionada. Muito feliz mesmo, porque é a 
sensação de dever cumprido." (Professor 1).

O reconhecimento por meio do julgamento de beleza, e como este ocorre, nota-se, por meio dos professores substitutos entrevistados, que tal reconhecimento não costuma ser legitimado pelos pares, pois muitos professores efetivos desrespeitam os professores substitutos, desqualificando o seu trabalho como de menos-valia, dificultando a identidade docente desses profissionais.

O reconhecimento no trabalho, de modo geral, expressa o sentimento de valorização, de sua importância, do quanto o trabalhador é significativo para a organização e para a sociedade, aliado ao sentimento de aceitação e admiração, de possuir liberdade para demonstrar sua individualidade, seu modo de pensar, organizar e falar sobre o próprio trabalho. Assim, o trabalhador resgata o sentido do trabalho, aumenta o prazer e mantém a saúde mental, tão importante para o exercício profissional.

Segundo Mancebo (2007), no caso dos docentes, é possível a percepção de espaços, nas instituições de ensino, de trocas afetivas e conhecimentos, além da produção de novos sentidos ao trabalho docente. Ou seja, a construção de momentos prazerosos para este profissional permite dialeticamente o desenvolvimento da tarefa e, ao mesmo tempo, proporciona uma sensação de bem-estar.

Os relatos ilustram bem o essa autora mencionou:

"Mesmo quando eu digo terminou, tão liberados. Eh professora! Valeu, viu? Gostei! Essa fala de aluno, ela é maravilhosa." (Professor 2).

"É quando os alunos participam, quando eles demonstram interesse." (Professor 3).

"Quando a gente vai pro laboratório e os alunos fazem o experimento e entendem. Eu saio daqui mesmo com a sensação de felicidade. (...) Aí eles ficam pedindo, ah vamos fazer tal coisa. (...) Isso me dá uma sensação de prazer." (Professor 9).

Percebe-se, assim, que a subjetividade no trabalho do professor substituto é marcada por processos antagônicos de prazer e sofrimento, permeada por um processo de perversa precarização e subsunção dessa força de trabalho ao capital.

\section{Considerações finais}

Retomando o objetivo deste artigo que analisou as vivências de prazer e sofrimento no trabalho dos professores substitutos de uma universidade federal, a partir das particularidades deste vínculo, 
pode-se destacar a conjuntura de precarização a qual o professor substituto está inserido por meio de um contrato por tempo determinado, com sobrecarga de trabalho, refletindo, assim, o modo de produção da acumulação flexível, por meio de um Estado gerencialista que tenta adequar as universidades públicas ao modelo da "fábrica enxuta".

As análises indicaram que muitos destes professores substitutos estão envolvidos na atmosfera de alienação do processo capitalista, sob condições históricas objetivas e subjetivas determinadas, dentre elas: relações de poder, submissão, sobrecarga de trabalho, submetendo-se sem questionamentos, uma vez que tais profissionais alimentam a expectativa de retorno à instituição como professor efetivo, em um verdadeiro controle de sua subjetividade.

Os participantes deste estudo apresentaram uma subjetividade marcada pelas ambivalências de prazer e sofrimento no trabalho. No que se refere à situação de prazer, está atrelada, em geral, ao relacionamento com os alunos e ao reconhecimento do seu trabalho por estes. Já os momentos de sofrimento são permeados por injustiças e submissão, revelando também o predomínio de defesas psíquicas individuais, em detrimento da proteção coletiva.

A identidade docente é afetada no caso de alguns professores substitutos, uma vez que estes profissionais não conseguem, muitas vezes, sentirem-se pertencentes à categoria docente, devido ao vínculo provisório. Por outro lado, alguns acreditam que estão contribuindo para o desenvolvimento dos alunos, construindo, assim, a sua identidade e o seu fazer docente, mesmo frente aos conflitos psíquicos e às dificuldades.

É inegável que a universidade pública enquanto espaço de construção de saberes se faz a partir da defesa do trabalho docente, cujo cerne seja a dignidade, o respeito e o reconhecimento. Há necessidade sim de políticas públicas na área da educação que priorizem o docente e a docência, estimulando novos concursos públicos, a fim de evitar déficits, não admitindo, portanto, que professores substitutos sejam "pau pra toda obra", contribuindo, assim, na manutenção da saúde mental dos professores. Desse modo, a subjetividade no trabalho e a identidade do professor substituto poderão ser construídas em alicerces mais prazerosos, com menos sofrimento e adoecimento.

Alves, G. (2000). O Novo (e Precário) Mundo do Trabalho- Reestruturação 
Produtiva e Crise do Sindicalismo.

São Paulo: Boitempo.

Alves, G. (2007). Dimensões da reestruturação produtiva: Ensaios de sociologia do trabalho (2a ed.). Londrina: Praxis.

Antunes, R. (2005a). Os sentidos do trabalho: Ensaio sobre a afirmaçãoe a negação do trabalho. (7a reimp.) São Paulo: Boitempo.

Antunes, R. (2005b). O caracol e sua concha: Ensaios sobre a nova morfologia do trabalho. São Paulo: Boitempo.

Chesnais, F. (1996). A mundialização do capital. São Paulo: Xamã.

Ciampa, A. D. C. (1989). Identidade. In S. T. M.Lane, \& W. Codo (Eds.), Psicologia social: $O$ homem em movimento (pp. 58-75). São Paulo: Brasiliense.

Coriat, B. (1994). Pensar pelo avesso: $O$ modelo Japonês de trabalho e organização. Rio de Janeiro: UFRJ.

Costa, S. H. B. (2013). Sentido do trabalho. In F. O. Vieira, A. M. Mendes \& A. R. C. Merlo (Orgs.). Dicionário crítico de gestão e psicodinâmica do trabalho (pp. 375379). Curitiba: Juruá.

Dejours, C. (2004). Addendum: Da psicopatologia à psicodinâmica do trabalho. In Lancman, S. \& Sznelwar, L.I (Eds.), Christophe Dejours: Da psicopatologia à psicodinâmica do trabalho (Cap. 1). Brasilia: Fiocruz.

Dejours, C. (1992). A loucura do trabalho: Estudo de psicopatologia do trabalho (5a ed.). São Paulo: Cortez.

Faria. J. H. de (2013). Sequestro da subjetividade. In F. O. Vieira, A. M. Mendes \& A. R. C. Merlo (Orgs.).
Dicionário crítico de gestão e psicodinâmica do trabalho. (pp. 381389). Curitiba: Juruá.

Guareshi, P. (2001). Pressupostos psicossociais da exclusão: Competitividade e culpabilização. In B. Sawaia (Ed.), As artimanhas da exclusão: Análise psicossocial e ética da desigualdade social (pp. 143-157). Petrópolis: Vozes.

Koehler, S. E. (2006). A trajetória institucional/docente do professor substituto da UFSM. (Dissertação de mestrado). Universidade de Federal de Santa Maria, Santa Maria, RS, Brasil.

Latieri, R. (2017, agosto 28). Uerj volta às aulas em meio a clima de insegurança. Jornal do Brasil. Recuperado de http://www.jb.com.br/rio/noticias/201 7/08/28/uerj-volta-as-aulas-em-meioa-clima-de-inseguranca/

Lei $n^{o} 12.772$, de 28 de dezembro de 2012. Dispõe sobre a estruturação do Plano de Carreiras e Cargos de Magistério Federal; sobre a Carreira do Magistério Superior, de que trata a Lei no 7.596, de 10 de abril de 1987, e dá outras providências. Recuperado de http://www.planalto.gov.br/ccivil_03/ ato2011-2014/2012/lei/112772.htm

Lei $n^{\circ}$ 8.745, de 09 de dezembro de 1993. Dispõe sobre a contratação por tempo determinado para atender a necessidade temporária de excepcional interesse público, nos termos do inciso IX do art. 37 da Constituição Federal e dá outras providências. Recuperado de http://www.planalto.gov.br/ccivil_03/ Leis/L8745cons.htm

Lima, S. C. C. (2013). Reconhecimento no trabalho. In F. O. Vieira, A. M. Mendes \& A. R. C. Merlo (Orgs.). Dicionário crítico de gestão e psicodinâmica do trabalho. (pp. 351355). Curitiba: Juruá. 
Macêdo, K. B. \& Heloani, R. (2013). Identidade. In F. O. Vieira, A. M. Mendes \& A. R. C. Merlo (Orgs.) Dicionário crítico de gestão e psicodinâmica do trabalho. (pp. 219223). Curitiba: Juruá.

Mancebo, D. (2007). Trabalho docente, sobreimplicação e prazer. Psicologia: Reflexão Crítica, 20(1), 74-80. doi: http://dx.doi.org/10.1590/S0102$\underline{79722007000100010}$

Marx, K. (1989). O Capital: Processo de produção do capital: Livro Primeiro. (vol.1. 13a ed). Rio de Janeiro: Bertrand.

Mendes, A. M. (2007). Da psicodinâmica à psicopatologia do trabalho. In A. M. Mendes (Ed.), Psicodinâmica do trabalho: Teoria, métodos e pesquisas (pp. 29-48). Rio de Janeiro: Casa do Psicólogo.

Ministério da Educação (MEC) (2012). Relatório sobre a expansão nas universidades federais. Brasillia.

Moraes, R. D. (2013). Estratégias Defensivas. In Vieira, F. O., Mendes, A. M., Merlo \& A. R. C. (Eds.), Dicionário crítico de gestão e psicodinâmica do trabalho (pp. 153158). Curitiba: Juruá.

Nogueira-Martins, M. \& Bógus, C. (2004). Considerações sobre a metodologia qualitativa como recurso para o estudo das ações de humanização em saúde. Saúde e Sociedade, 13(3), 44-57. doi: http://dx.doi.org/10.1590/S0104$\underline{12902004000300006}$

Pinto, M. J. B. (2010). Professor substituto. In D. A. Oliveira, A. M. C. Duarte \& L. M. F. Vieira (Eds.), Dicionário de trabalho, profissão e condição docente. Belo Horizonte: Faculdade de Educação/UFMG.
Ramos, M. (2002). A pedagogia das competências: Autonomia ou adaptação? (2a ed.). São Paulo: Cortez.

Ribeiro, C. \& Leda, D. (2016). O trabalho docente no enfrentamento do gerencialismo nas universidades públicas brasileiras. Educação em Revista, 32 (4), p. 97-117. doi http://dx.doi.org/10.1590/0102$\underline{4698161707}$

Vieira, L. (2014, março 12). Apesar de proibição da Justiça, Uerj renova com professores substitutos. Globo Educação. Recuperado de https://oglobo.globo.com/sociedade/ed ucacao/apesar-de-proibicao-da-justicauerj-renova-com-professores$\underline{\text { substitutos-11858145 }}$

Zorzo, E. S. (2010). A redução do quadro de professores substitutos como pauta de negociação na universidade federal do Rio Grande do Sul. (Monografia de Especialização). Universidade Federal do Rio Grande do Sul, Porto Alegre, RS, Brasil. Recuperado de http://hdl.handle.net/10183/34500

\section{Data de Submissão: 29/01/2018 Data de Aceite: 05/07/2018}

